\title{
A relevância da disciplina de língua portuguesa: percepções de alunos na modalidade EJA profissionalizante
}

\author{
Beatriz Galhardo Oliva Sanches ${ }^{1}$ \\ Orcid: https://orcid.org/0000-0002-4067-5251 \\ Helena Gemignani Peterossi ${ }^{2}$ \\ Orcid: https://orcid.org/0000-0003-1163-7181 \\ Rodrigo Avella Ramirez ${ }^{3}$ \\ Orcid: https://orcid.org/0000-0001-8468-2851
}

\begin{abstract}
Resumo
A Educação Profissional, mais especificamente a de nível médio integrada à modalidade de Educação de Jovens e Adultos (EJA), é um campo marcado pela falta de regularidade, carente de estudos, em que muitas questões surgem e se fazem necessárias. Neste cenário, o presente trabalho surgiu como uma reflexão sobre a Educação Profissional e Tecnológica, o papel dos docentes e da escola na formação dos sujeitos, tendo em vista seus marcos legais em nosso país, em especial as iniciativas e programas para o Ensino Técnico Integrado ao Médio na modalidade EJA, no contexto do Centro Paula Souza. Outro aspecto examinado, é a percepção discente sobre o componente curricular "Língua Portuguesa, Literatura e Comunicação Profissional" proposto no itinerário formativo em questão. Desta forma, este artigo pretende analisar a experiência de uma Escola Técnica Estadual, para investigar como os alunos percebem a importância da disciplina, e como compreendem a aquisição das habilidades linguísticas.
\end{abstract}

Palavras-chave: Políticas Públicas em Educação; Educação de Jovens e Adultos; Educação Profissional.

\begin{abstract}
Vocational Education, more specifically the secondary level integrated to the Youth and Adult Education (EJA), is a field marked by lack of regularity, lacking studies in which many issues arise and become necessary. In this scenario, the present paper emerged as a reflection on Vocational and Technological Education, the role of teachers and schools in the training of individuals in view of the legal frameworks in Brazil, in particular initiatives and programs for Integrated Technical Education, EJA modality, in Centro Paula Souza's context. Another key fact is the student's' perception of the curriculum component "Portuguese Language, Literature and Professional Communication" proposed in the mentioned formative journey. To that end, the experience of a State Technical School is investigated through questionnaires with students in order to observe their perceptions toward the importance of the curriculum subject in question and how they understand the language skills acquisition.
\end{abstract}

Keywords: Educational Public Policies; Youth and Adult Education; Vocational Education.

\footnotetext{
${ }^{1}$ Mestre em Gestão e Desenvolvimento da Educação Profissional, Centro Paula Souza, beatrizgosanches@gmail.com

2 Doutora em Educação, Centro Paula Souza, hgemig@bol.com.br

${ }^{3}$ Doutor em Educação, Arte e História da Cultura, Centro Paula Souza, roram1000@hotmail.com
} 


\section{Introdução}

O cotidiano escolar proporciona aos seus atores uma riqueza de experiências, à medida que não se encontram muitos espaços para uma atenção mais significativa sobre, principalmente, a prática docente. Raros são os momentos dedicados ao estudo mais aprofundado, por exemplo, da função da escola, do papel e da formação do docente de ensino técnico ou, ainda, da legislação que regulamenta e determina as diretrizes específicas para Educação Profissional e Tecnológica. Esse espaço e momentos foram proporcionados a esta pesquisadora dentro do Programa de Mestrado Profissional em Gestão e Desenvolvimento da Educação Profissional ofertado pela Unidade de Pós-graduação, Extensão e Pesquisa do Centro Estadual de Educação Tecnológica Paula Souza.

A Educação Profissional carrega o compromisso de formar sujeitos capacitados para o mundo do trabalho e, consequentemente, é responsável por proporcionar aos seus alunos os conhecimentos necessários, e desenvolver as competências e habilidades exigidas por esse "mundo". Considera-se que, essa seria uma das definições mais comuns sobre a Educação Profissional, contudo, à medida que se pretende entender essa modalidade, podemos observar algumas de suas especificidades as declarações assumidas como ponto de partida, que convertem mais em indagações, do que em novas afirmações. O que se entende por Educação Profissional? "Mundo do trabalho"? Quem são esses sujeitos? O que podemos compreender como formação, capacitação, qualificação, competências e habilidades? Qual a função da escola e mais especificamente as escolas de ensino técnico? Quais são os conhecimentos que ela deve difundir?

Ao ponderar não só a modalidade da Educação Profissional, mas também a considerada "Tradicional", ou propedêutica, nota-se, à margem de ambas, a esfera da Educação de Jovens e Adultos (EJA) em seus níveis: fundamental, médio e médio integrado ao Ensino Técnico. São terrenos quase que desconhecidos, carentes de estudos, em que muitas outras questões surgem e se fazem necessárias. Nesse contexto de questionamentos, o presente artigo surge como uma reflexão sobre a Educação Profissional e Tecnológica, seu papel na formação dos sujeitos tendo em vista seus marcos legais em nosso país, em especial as iniciativas e programas para o Ensino Técnico Integrado ao Médio na modalidade de Educação de Jovens e Adultos (EJA) no contexto do Centro Paula Souza.

Outro aspecto importante para o desenvolvimento deste trabalho, foi pontuar a questão da comunicação como um dos objetos de análise e estudo. A comunicação faz parte do cotidiano, contudo, eventualmente refletimos sobre o nosso próprio idioma e sua importância no mundo do trabalho.

O questionamento que norteia este artigo advém da vivência da pesquisadora e a sua observação do ingresso de um novo perfil de aluno na unidade em que leciona. Assim, em um curso técnico na modalidade EJA, como se constitui a percepção de desenvolvimento das habilidades linguísticas em língua portuguesa?

O corpo docente é eminentemente composto por professores licenciados em Letras, ou seja, oriundos da academia e que neste momento se viram responsáveis por uma disciplina que demandava conhecimentos do "mundo do trabalho", o que ocasionou um estranhamento inicial entre a formação do docente e conteúdo da disciplina. Além da inexperiência em ministrar aulas em um curso novo na unidade, com alunos e necessidades diferenciadas, a nomenclatura, e a estrutura curricular da disciplina: "Língua Portuguesa, Literatura e Comunicação Profissional", configuraram-se como o ponto de partida e, dessa forma, o questionamento norteador do presente trabalho. Por conseguinte, percebe-se um conflito, e a necessidade de entendimento entre o que o plano de curso determina, e quais seriam, também, as concepções dos docentes que ministram as aulas de "Comunicação", ou mais especificamente, "Comunicação Profissional" na Educação de Jovens e Adultos Profissionalizante. 


\section{Metodologia}

A escolha do objeto de estudo advém da vivência da pesquisadora nos cursos de Ensino Técnico Integrado ao Médio (ETIM) e, a partir do segundo semestre de 2016, em um Curso Técnico Integrado ao Ensino Médio na Modalidade de Jovens e Adultos (EJA) Cozinha, na Escola Técnica Estadual Benedito Storani, que pertence ao Centro Estadual de Educação Tecnológica Paula Souza (CEETEPS).

O presente artigo é composto por uma breve análise bibliográfica no que diz respeito ao papel da escola no ensino de jovens e adultos, em especial as contribuições da disciplina: "Língua Portuguesa, Literatura e Comunicação Profissional", bem como algumas considerações sobre o Documento Base do Programa Nacional de Integração da Educação Profissional com a Educação Básica na Modalidade de Educação de Jovens e Adultos (PROEJA).

Um questionário estruturado foi aplicado para verificar e comparar o quão próxima é a percepção de alunos e professores sobre o curso e sobre a disciplina. O trabalho, portanto, caracteriza-se como uma pesquisa descritiva, de abordagem qualitativa.

\section{O papel da escola no ensino de jovens e adultos}

Zabala (1998, p.27) nos convida a refletir sobre a função social do ensino e das atribuições da escola através de questionamentos desafiadores: "o papel da escola deve ser seletivo e propedêutico? Ou deve cumprir outras funções? [...] Quais são as nossas intenções educacionais? O que pretendemos que nossos alunos consigam?". O autor explicita que dentre as diversas atividades do professor cabe a esse saber identificar os fatores que incidem no crescimento dos alunos e, também, avaliar se a intervenção realizada é coerente com a ideia de que ele tem da função da escola, e, portanto, da sua função social como educador. Para entender melhor tal processo, Zabala (1998) recorre à proposta de classificar as capacidades do ser humano propostas por C. Coll (capacidades cognitivas ou intelectuais, motoras, afetivas, de relação interpessoal e de inserção e atuação social) e, novamente, pondera sobre quais delas são de fato priorizadas no ensino "regular" ou "tradicional" e quais o sistema educativo deveria dar importância. O autor afirma que:

A resposta a estas perguntas é a chave para determinar qualquer atuação educacional [...]. Educar quer dizer formar cidadãos e cidadãs, que não estão parcelados em compartimentos estanques, em capacidades isoladas. [...] A capacidade de uma pessoa se relacionar depende das experiências que vive e as instituições educacionais são um dos locais [...] para se estabelecer vínculos e relações que condicionam e definem as próprias concepções pessoais sobre si mesmo e sobre os demais. A posição dos adultos frente à vida [...] a forma de estabelecer as comunicações na aula, o tipo de regras de jogo e de convivência incidem em todas as capacidades da pessoa (ZABALA, 1998, p.28).

Dessa forma, cabe ao professor buscar o entendimento e a influência que tais experiências carregam, e intervir para que sejam as mais positivas possíveis para o desenvolvimento dos alunos, o que nos remete à ideia de coerência que se configura como tarefa indissociável das práticas docentes. Ressalta-se a preocupação de Zabala com a comunicação docente, outro tema que esta pesquisa pretende examinar através das entrevistas com docentes e alunos selecionado. Para Peterossi e Menino (2017, p.105), a escola técnica tem uma finalidade "socioprofissional" e 
Seu papel é permitir o acesso aos saberes e às habilidades tal como requisitados socialmente. Ora, em nossa sociedade altamente tecnológica, a escola deve apresentar uma integração orgânica entre formação técnica e a formação escolar geral, de modo a estabelecer uma significação cultural com os valores formativos inerentes aos sabres e às práxis dos profissionais a serem por ela formados. (PETEROSSI, MENINO, 2017, p.105).

Os autores, à vista disso, trazem à discussão a conhecida tensão na esfera da educação profissional: a função dessa escola é formar para "o saber" ou "formar para o trabalho" e a preocupação em criar "mecanismos de ação" mais do que "de problematizações".

Em relação à Educação de Jovens e Adultos, a questão essencial refere-se às concepções de ensino e aprendizagem adequadas à continuidade da formação escolar do trabalhador (PONTUSCHA, 2013, p.131). Retoma-se, assim, a questão deste artigo, que pretende trazer a reflexão dos docentes acerca de suas práticas e, considerando como ponto de partida a afirmação de Pontuscha, quais seriam "as concepções de ensino e aprendizagem adequadas à continuidade da formação escolar do trabalhador"? Destaca-se que, no contexto escolhido para análise, não são todos os alunos que se encontram inseridos no mercado de trabalho, considerado "formal". Nesse cenário, o que se pode admitir como "adequado", frente ao perfil dos alunos, ao currículo proposto pela instituição e às ferramentas disponíveis aos docentes e discentes?

Barato (2015, p.13) desenvolveu um extenso estudo sobre Valores em Educação Profissional, e declara que "boa parte do desenvolvimento de valores ocorre no âmbito do currículo oculto [...] Todas as atividades escolares refletem valores e promovem visões de mundo que positiva ou negativamente contribuem para o desenvolvimento socioafetivo".

A modalidade EJA constitui-se como o agrupamento de alunos que se encontram fora da série adequada para a idade, devido aos mais diversos motivos e com diferentes trajetórias de vida que ao longo dos anos acumularam diferentes experiências em seus trabalhos e nas relações com familiares e amigos. Logo, estabelece-se um diálogo entre as reflexões anteriores mais gerais sobre a importância das experiências com o discurso de Pontuscha (2013), que salienta o papel do professor para a clientela em questão:

O conjunto dessas experiências diferencia profundamente a educação daquela de crianças e adolescentes, e precisa ser considerada pelo professor ao pensar o seu plano de curso. Não é conveniente utilizar metodologias que os infantilizem e concorram para excluí-los da escola, em vez de aproveitar o seu conhecimento como ponto de partida para ampliá-lo no relacionamento com os saberes escolares (PONTUSCHA, 2013, p.131).

Podemos afirmar que há praticamente um consenso entre as teorias que discorrem sobre a relação entre professor-aluno, a ideia de que quando o professor considera os saberes acumulados (prévios), está fazendo com que o aluno sinta-se importante e valorizado como cidadão. É preciso, porém, pensar que o acesso ao saber acadêmico, por parte dos alunos, implica inclusão em todo um universo de conhecimentos e também em um redimensionamento dos próprios conhecimentos (PONTUSCHA, 2013, p.133).

Novamente, percebe-se o parecer da autora quanto à adequação, que agora volta-se para o plano de curso. O propósito deste estudo não é realizar uma extensa descrição dos programas e currículos, mas alguns pontos do Plano de Trabalho Docente (PTD) foram elencados para uma breve descrição e análise no terceiro capítulo.

Barato $(2015$, p.14) revela que seu estudo nasceu de casos de insucesso, e que no caso da educação profissional e tecnológica, mais especificamente, o tratamento dos valores ignora, muitas vezes, as práticas sociais significativas presentes em atividades de trabalho. Em outras 
palavras, a EPT é fortemente marcada pela divisão entre teoria x prática e no campo dos valores a oposição se dá entre técnica $\mathrm{x}$ humanismo.

Tendo em vista esse processo de encontro com o saber acadêmico e técnico, os alunos que retornam aos bancos escolares já adultos ou fora da série escolar, buscam a inserção social que a formação (além das certificações) confere. Portanto, "falar e escrever bem" podem ser um mecanismo que reforça a autoconfiança desses alunos. Compreender ideias alheias e expressar verbalmente ideias próprias requer a assimilação de um saber acadêmico ou "escolar":

Se considerarmos, como fins da escola a preparação do aluno para a vida, incluindo nela a preparação para o trabalho, o papel da educação escolar passa a ser o de desenvolvimento de capacidades fundamentais para o autodesenvolvimento, a relação interpessoal, a vida em sociedade e o trabalho produtivo [...] Há interdependência entre formação integral do cidadão e a educação profissional. De um lado, o alcance dos objetivos da educação geral desenvolve habilidades e fornece conhecimentos que são úteis para a sua formação profissional. Por outro lado, a educação profissional específica também concorre para a formação integral do aluno (MORAES; KÜELLER, 2016, p.40-42).

Conclui-se, dessa forma, que a função da escola, e, portanto, da educação profissional, não pode limitar-se à exposição dos alunos aos conhecimentos científicos, ou "saberes sistematizados": Assim, acredita-se que sejam necessárias algumas considerações sobre o que se entende como formação integral ou, ainda, quais são os objetivos do Ensino Médio Integrado.

\section{Comunicação e a disciplina: "Língua Portuguesa, Literatura e Comunicação Profissional"}

Tardif (2014) propõe uma definição de pedagogia enquanto "tecnologia da interação humana", e uma análise do trabalho dos professores em função de um modelo interativo. Dessa forma, o autor enuncia a pedagogia nos seguintes termos:

A pedagogia é o conjunto de meios empregados pelo professor para atingir seus objetivos no âmbito das interações educativas com os alunos. Noutras palavras, do ponto de vista da análise do trabalho, a pedagogia é a "tecnologia" utilizada pelos professores em relação ao seu objeto de trabalho (os alunos), no processo de trabalho cotidiano, para obter um resultado (a socialização e a instrução) (TARDIF, 2014, p.117).

O autor enfatiza que o ensino é uma atividade humana, um trabalho interativo, ou seja, um trabalho baseado em interações entre as pessoas.

Em suma, se o ensino é mesmo uma atividade instrumental, trata-se de uma atividade que se manifesta concretamente no âmbito das interações humanas e traz consigo, inevitavelmente, a marca das relações humanas que a constituem. Nesse caso, o professor é um "trabalhador interativo" (TARDIF, 2014, p.118).

Citelli (2004) buscou aproximar os debates em torno da produção de sentidos no âmbito da comunicação paralelamente com o tópico da educação. A escola está sendo pensada, desse modo, como espaço meditativo cada vez mais cruzado pelas novas linguagens e pelas transformações científicas, tecnológicas, culturais e de comportamentos que marcam o mundo contemporâneo (CITELLI, 2004, p.83). Ainda, de acordo com o autor

[...] a escola deve ser um espaço de trabalho onde ocorre a passagem do lugar comum para o conhecimento elaborado, num movimento que visa fazer da matéria empírica conceito. E que, igualmente, ensina o sujeito a reconhecer-se no processo de transformação, transformando-se. Por isso, a necessidade de o aluno ser entendido 
como sujeito com linguagem que exercita um discurso central para a efetivação do ato pedagógica. (CITELLI, 2004, p.111).

As interações com os alunos não constituem um campo periférico, elas são o núcleo do trabalho dos professores e, por essa razão, determinam a própria natureza dos procedimentos e, logo, da pedagogia.

Figaro (2008, p.18) parte da ideia de que o campo científico da comunicação é o responsável para explicar a realidade da sociedade contemporânea e suas formas de expressão: para tratar da comunicação dessa perspectiva, estudamos o binômio comunicação e trabalho tendo como hipótese teórica que o mundo do trabalho é mediação fundamental nas relações de comunicação.

A autora ampara-se nos Estudos da Recepção que buscam entender as mediações que permeiam o processo comunicativo:

\begin{abstract}
De que maneira a comunicação se processa como interação, como e em que conjunto de relações ela constrói sentidos e em que esferas, grupos e situações tais sentidos são construídos. É esta uma tarefa complexa, pois, os sentidos, como construções de um corpo social determinado, não deixam de ser assimétricos, afeitos à intempestividade das diferentes realidades dos grupos sociais, das culturas locais e particulares, das práticas sociais do cotidiano, dos interesses pontuais dos grupos por identidade e das subjetividades (FIGARO, 2008, p.19).
\end{abstract}

A autora também destaca que a comunicação ocupa lugar de relevância na constituição do ser social, evidenciando-a, como aspecto que se soma às ordenações do mundo do trabalho, transformando instrumentos, práticas e rotinas, atuando, muitas vezes, inclusive também como ferramenta. Em suma, a comunicação é sinônimo de interação humana e é entendida em relação intrínseca ao trabalho, à fala, à cultura, aspectos fundantes da sociedade humana. Logo, o ser humano é um ser de comunicação e a linguagem está dialeticamente vinculada à atividade do homem na sociedade (FIGARO, 2008, p.86).

\title{
5 O PROEJA - Considerações sobre o documento base
}

Através das alterações promovidas no Decreto $n^{0}$ 5.840/2006 (documento base), o PROEJA transformou-se em um Programa Nacional de Integração da Educação Básica na modalidade EJA e pode ser ofertado pela Rede Federal de Educação Profissional, Científica e Tecnológica (Centros Federais de Educação Tecnológica - CEFETs; Escolas Técnicas Federais - EFTs, Escolas Agrotécnicas Federais - EAFs e Escolas Técnicas vinculadas às Universidade Federais), pelas esferas estaduais e municipais e por entidades privadas nacionais de serviço social, aprendizagem e formação profissional vinculadas ao sistema sindical (Sistema S).

Cabe destacar que algumas dessas instituições foram convocadas a implantar o PROEJA - como a Rede Federal de Educação Profissional e Tecnológica, pois como assumem os autores Moura e Henrique (2012, p. 116), algumas características dessa Rede potencializam a função que as instituições a elas vinculadas podem assumir nesse processo, tais como: a presença em quase todos os estados da federação e a tradição vinculada à qualidade já reconhecidas no ensino médio e na educação profissional técnica de nível médio.

Por esse motivo, provavelmente, a maioria dos estudos de tal modalidade circular no contexto dos CEFETs e outras instituições pertencentes à Rede Federal - talvez a obrigatoriedade dessa implantação instituiu reformulações e novas reflexões acerca do tema nesses ambientes. Dessa maneira, este trabalho se justifica uma vez identificada a ausência de estudos de como os Cursos Técnicos Integrados ao Ensino Médio na Modalidade de Jovens e Adultos (EJA) foram concebidos e incorporados pelo Centro Paula Souza. 
O surgimento do PROEJA, em 2006, apontava, de acordo com os documentos oficiais, duas finalidades, sendo elas: enfrentar as descontinuidades e o voluntarismo que marcam a modalidade EJA em nosso país, e integrar a educação básica em uma formação profissional que contribua para a integração socioeconômica de qualidade do coletivo de jovens e adultos. (MOURA; HENRIQUE, 2012, p.116).

Contudo, os autores, de forma taxativa, constatam que, é pouca ou quase nenhuma a experiência da mencionada Rede no que se refere ao trabalho com a modalidade Educação de Jovens e Adultos, o que resulta em diversas limitações ao processo de implantação do programa.

O Documento Base do PROEJA (BRASIL, 2007, p.14) fornece uma tabela com dados da Pesquisa Nacional por Amostra de Domicílios (PNAD), realizada em pelo Instituto Brasileiro de Geografia e Estatística (IBGE), que foram organizados em gráficos apresentados nas Figuras 1 e 2. Em 2003, conforme a Figura 1, o total de habitantes chegava a quase 174 milhões e apesar do destaque para as quase 23 milhões de pessoas que possuíam 11 anos de estudo e, portanto, concluíram o Ensino Médio, esse contingente representava apenas $13 \%$ do total da população do país:

Figura 1 - Percentual de habitantes por anos de estudo A

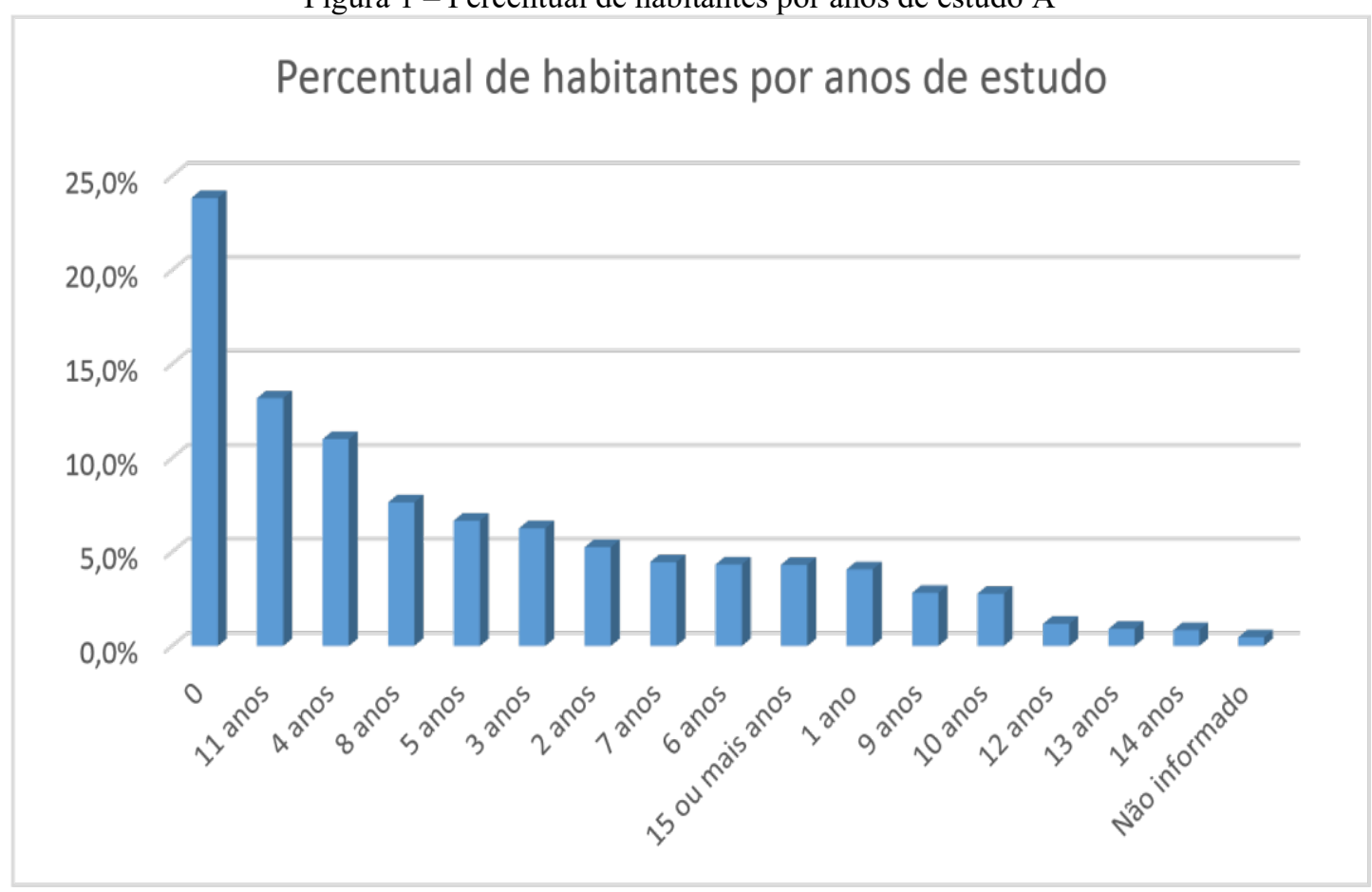

Fonte: BRASIL. Ministério da Educação. Programa de Integração da Educação Profissional e Técnica de Nível Médio Integrada ao Ensino Médio da Modalidade de Educação de Jovens a Adultos - PROEJA. Documento Base (2007, p.14)

Nota: Dados trabalhados pela autora

No entanto, o percentual mais elevado, e que representa quase um quarto da população encontrava-se na faixa correspondente a zero anos de estudo: 


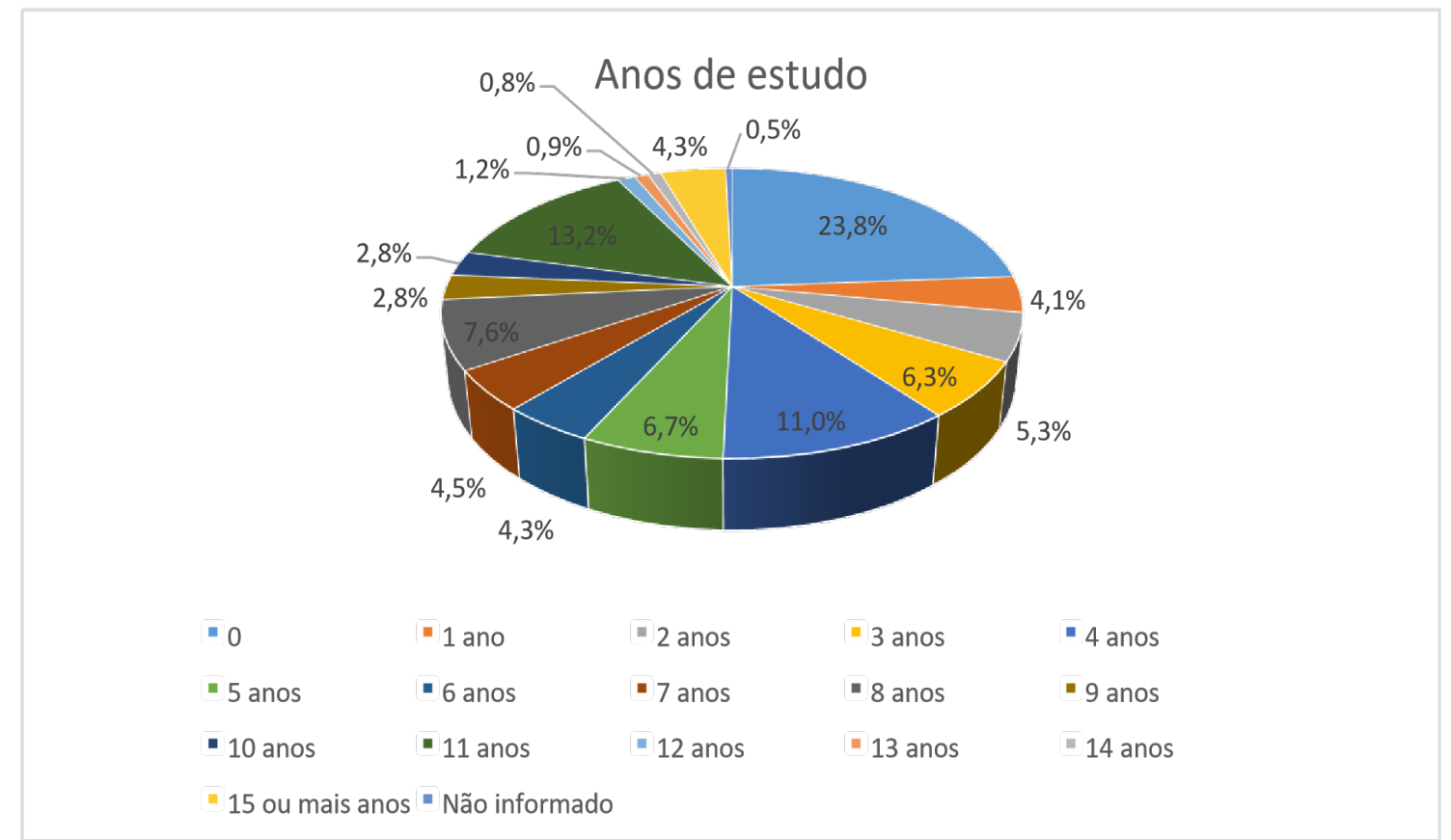

Fonte: BRASIL. Ministério da Educação. Programa de Integração da Educação Profissional e Técnica de Nível Médio Integrada ao Ensino Médio da Modalidade de Educação de Jovens a Adultos - PROEJA. Documento Base (2007, p.14)

Nota: Dados trabalhados pela autora

De acordo com Manfredi (BRASIL, 2007, p.47), citada no Documento Base em questão, além de expressar uma decisão política de garantia de direitos, o Proeja, epistemologicamente, está fundamentado em um projeto educativo com fundamentos político pedagógicos emancipatórios e democráticos: a) A integração curricular visando a qualificação social e profissional articulada à elevação da escolaridade, construída a partir de um processo democrático e participativo de discussão coletiva; b) A escola formadora de sujeitos articulada a um projeto coletivo de emancipação humana; c) A valorização dos diferentes saberes no processo educativo; d) A compreensão e consideração dos tempos e espaços de formação dos sujeitos da aprendizagem; e) A escola vinculada à realidade dos sujeitos; f) A autonomia e colaboração entre os sujeitos e o sistema nacional de ensino; g) O trabalho como princípio educativo.

O Documento Base do Proeja, alicerçado nos fundamentos acima transcritos, considera que a Educação Profissional tem uma dimensão social intrínseca, ela extrapola a simples preparação para uma ocupação específica no mundo do trabalho e "postula a vinculação entre a formação técnica e uma sólida base científica, numa perspectiva social e histórico-crítica, integrando a preparação para o trabalho à formação de nível médio" (MANFREDI, 2016, p. 57).

\section{A ETEC Benedito Storani e o perfil dos alunos do curso técnico em cozinha integrado ao ensino médio na modalidade de jovens e adultos (EJA)}

A Escola Técnica Estadual Benedito Storani possui uma importante história e tradição dentro da cidade de Jundiaí. Em 6 de julho de 1945, a Secretaria de Agricultura de São Paulo instalou a Escola Prática de Horticultura de Jundiaí, momento que, a princípio, a fazenda deu espaço para a Escola. Em 8 de novembro de 1975 com a publicação do projeto de lei número 559/75, denominou-se Escola Estadual de $2^{\circ}$ Grau "Benedito Storani" e, desde então, passou por grandes transformações e está, atualmente, vinculada ao Centro Paula Souza e à Secretaria de Tecnologia Desenvolvimento Econômico e Turismo do Estado de São Paulo. 
Privilegiada quanto à sua localização no Município de Jundiaí, SP, a Escola se encontra em área de preservação ambiental anexa à Serra do Japi. A "ETEC BeSt", como é popularmente conhecida, está implantada numa área de 300 hectares $(3.000 .000 \mathrm{~m} 2)$, possui diversos setores agropecuários, conta com laboratórios e cozinhas disponíveis para os cursos nas áreas de Agropecuária, Alimentos, Cozinha, Nutrição e Química.

O curso de Técnico em Cozinha Integrado ao Ensino Médio na Modalidade de Educação de Jovens e Adultos (EJA) foi oferecido pela primeira vez na Etec Benedito Storani no segundo semestre de 2016 no período noturno.

O gráfico, abaixo, revela que $72 \%$ dos estudantes encontravam-se na faixa dos 30 aos 49 anos, contando com três alunos na faixa do 18 aos 20 e apenas um acima de 50.

Figura 3 - Distribuição dos alunos por faixa etária - EJA Cozinha

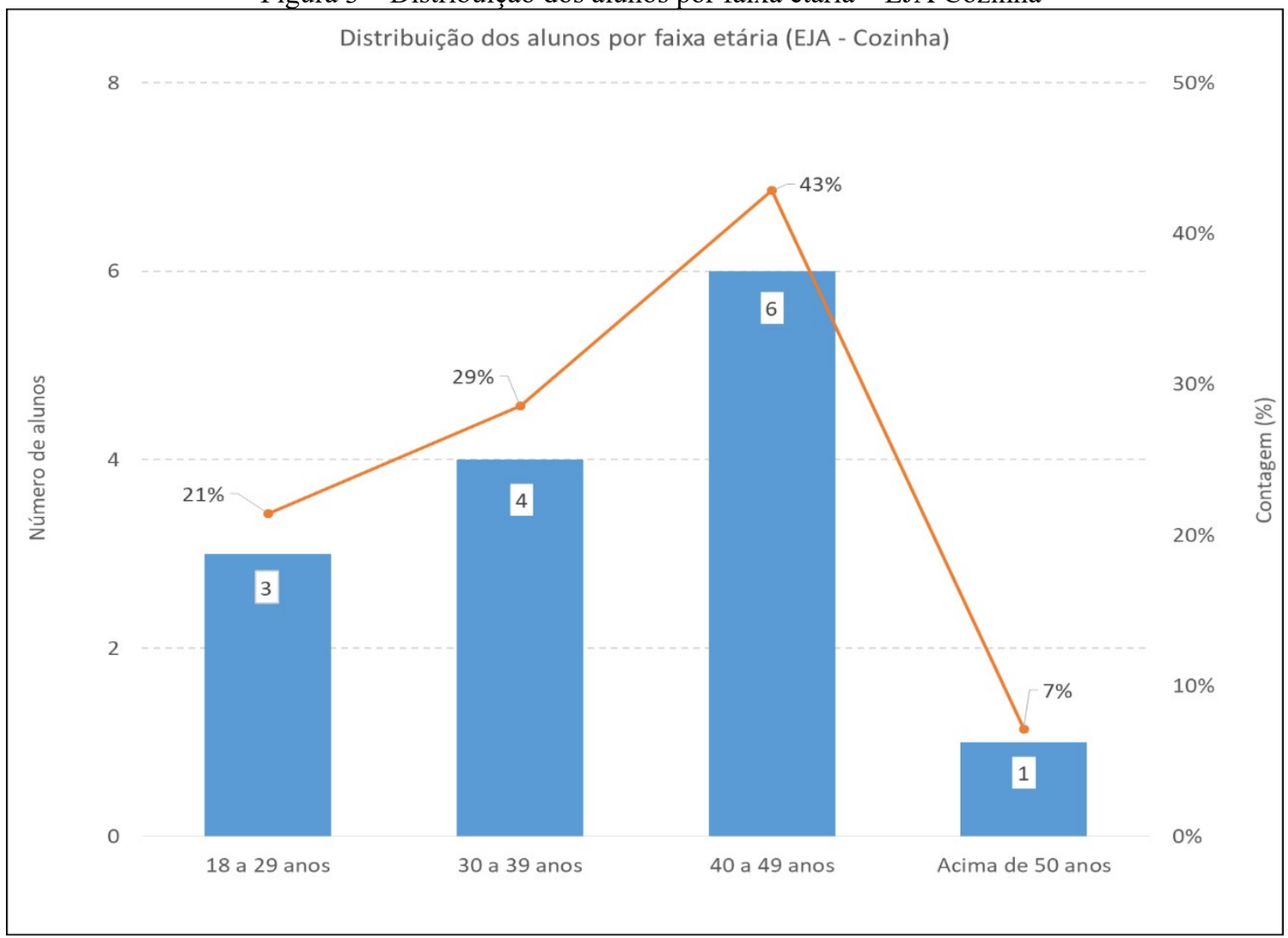

Fonte: CENTRO PAULA SOUZA. Mapeamento das Escolas Técnicas - Dados Gerais, Eixos Tecnológicos e Cursos Oferecidos. Mapeamento das Unidade do Centro Paula Souza 2016 - $2^{\circ}$ semestre.

Nota: Dados trabalhados pela autora

Logo, verificou-se que o curso atendeu, assim, a Emenda Constitucional $n^{\circ} 59$ da Constituição Federal, de 11 de novembro de 2009, que prevê em seu art. 208 uma das características primordiais da EJA: a oferta de educação gratuita ao aluno que se encontra fora da série escolar apropriada para a sua faixa etária. É válido também, ampliar essa observação uma vez que nesse quadro não se constata a já citada "juvenilização da clientela" como um traço dos cursos supletivos durante, principalmente, os anos de 1980 e 1990.

\section{Resultados e discussão}

Os alunos, que estavam em fase de conclusão do curso, foram convidados a participar do trabalho respondendo um questionário estruturado que, abordou desde temas mais gerais, 
como a quantidade de aulas práticas (área técnica) e a certificação obtida ao longo do período, até as mais específicas sobre a disciplina de "Língua Portuguesa, Literatura e Comunicação Profissional'".

Em sua maioria, os alunos apontaram que a quantidade de aulas do referido componente curricular atendeu as expectativas conforme os relatos a seguir e, de acordo com a Figura 4, abaixo: "Tinha muita dificuldade com a língua portuguesa, e graça as 2 professoras que tive durante o curso hoje consigo escrever melhor utilizando as pontuações."। "Conheci várias palavras que nunca tinha escutado falar."/ "eu acho as aulas de portuguesa foi muito importante aprendi muitas coisas e ainda faltas pois quanto mais nos estuda mais aprende mais E aumenta o nosso desempenho como falar e expressar sem medo de errar estas aulas foi muito importante."/ "Aprendi bastante, não apenas didaticamente mas também em situações do dia a dia." / "As aulas eram bem dinâmicas, e me deixou com muita vontade de aprender cada vez mais.”:

Figura 4 - Questionário alunos EJA Cozinha (questão 4)

Fonte: Questionário aplicado via Google Forms - dezembro de 2018

Na questão seguinte, igualmente, grande parte dos alunos respondeu de forma afirmativa que as aulas colaboraram para o desenvolvimento das habilidades de analisar, interpretar e produzir textos: "Com nossas aulas, passei a enxergar os textos de uma outra forma, entender melhor o que leio, e preocupar-me com o que eu escrevo."/ "Porque pra todas as entrevistas tem interpretação de textos e eu creio que eu estou preparada."/ "A professora sempre mandava atividades para casa, e olhava o caderno na aula seguinte, e isso de certa forma nos obrigava a ler e pesquisar mais, sobre a língua portuguesa."/ "Aprendi como elaborar textos, ajuda muito nos exames do ENEM."/ "Aprendi muita coisa que não sabia." / "Ficou mais claro a minha visão sobre um texto, sabendo como elaborar e obter aquilo que se precisa." I "Interpretação de texto é tudo. Sem isso é impossível exercer qualquer atividade." / Sim, dando oportunidade de entender a língua e sua aplicação no dia a dia." 
Figura 5 - Questionário alunos EJA Cozinha (questão 5)

5) Para você as aulas de Língua Portuguesa, Literatura e Comunicação Profissional colaboraram para analisar, interpretar e produzir textos?

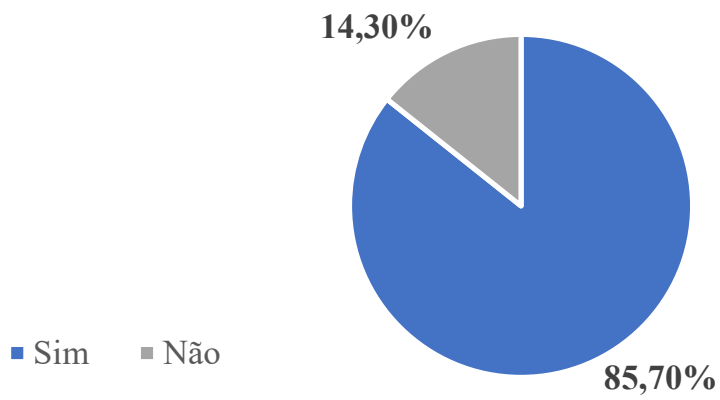

Fonte: Questionário aplicado via Google Forms - dezembro de 2018

Outro tema abordado foi se os alunos consideravam que o componente curricular os auxiliou na comunicação e na elaboração de textos de outras disciplinas do curso. Nesse item, conforme a Figura 6, a seguir, todos os alunos responderam de forma afirmativa, além de manifestarem ponderações sobre o uso da linguagem formal: "Eu não só melhorei, de fato eu aprendi." / "Por que eu não me preocupava com a escrita, mas percebi e aprendi que para fazer um cardápio e necessário ter combinações e uma escrita correta." / "A língua portuguesa ficou mais clara, regras que já nem lembrava mais também." / Me ajudou muito na elaboração do TCC." / "Durante o decorrer do curso, minha postura profissional ficou mais refinada com os ensinamentos. E minha visão ficou mais ampla." / "Facilitou muito para uma escrita direta e objetiva." / "Tivemos que usar muitas vezes uma linguagem formal."

Figura 6 - Questionário alunos EJA Cozinha (questão 8)

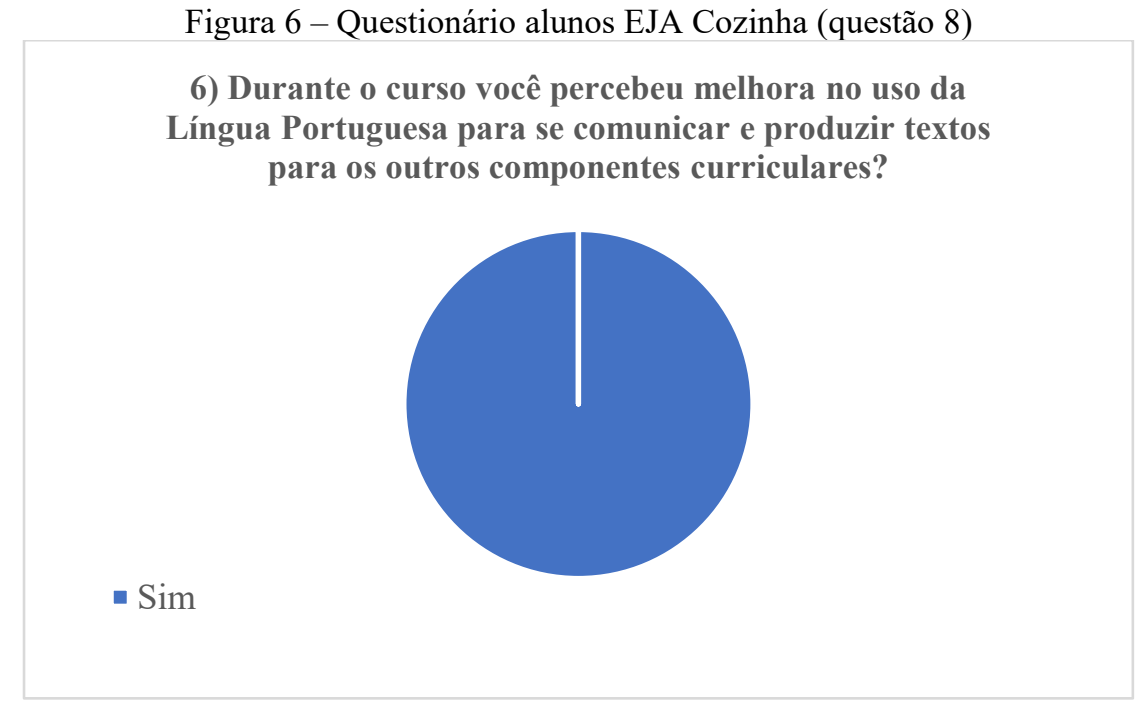

Fonte: Questionário aplicado via Google Forms - dezembro de 2018

Por fim, a última questão buscava saber se os alunos julgavam que os conhecimentos adquiridos ao longo do período, nas aulas de Língua Portuguesa, Literatura e Comunicação Profissional, colaboraram, ou poderiam contribuir, para a inserção no mercado de trabalho. 
Do mesmo modo, todos os alunos escolheram a opção afirmativa e, ainda, explicaram que: "Todo conhecimento só vem para somar, e como estamos falando da língua portuguesa, com certeza esse aprendizado será peça chave."/"Acredito que falar bem e escrever contam muito na hora de concorrer a uma vaga de emprego."/ "Muito pois hoje não tenho mais medo de escrever." / "Tivemos informações necessária para ingressar na área." / Com certeza, proporcionou uma melhor apresentação pro mercado de trabalho com uma postura mais confiante e objetiva." / "Sim, antes do curso eu tive a oportunidade de pegar aquela vaga na cozinha que só estava disponível porque ninguém queria ocupa-la. Depois do curso com o conhecimento adquirido eu cresci e mudei a minha posição. Antes lavava pratos, hoje sou cozinheiro. Mas lavo pratos também."

Figura 7 - Questionário alunos EJA Cozinha (questão 10)

10) Você julga que os conhecimentos adquiridos durante as aulas da disciplina Língua, Portuguesa, Literatura e Comunicação Profissional colaboram, ou podem colaborar, para sua inserção no mercado de trabalho?

- Sim

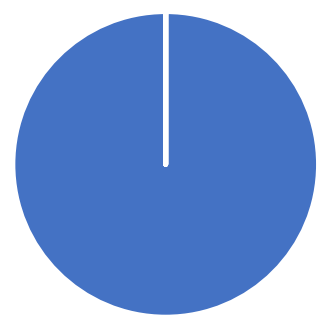

Fonte: Questionário aplicado via Google Forms - dezembro de 2018

\section{Considerações finais}

A pesquisa feita com os alunos do Técnico em Cozinha Integrado ao Ensino Médio na Modalidade de Jovens e Adultos (EJA) permitiu que os primeiros apontamentos do referencial teórico fossem contextualizados em uma situação real, dentro de um curso oferecido em uma das unidades do Centro Paula Souza. Tendo como foco a disciplina Língua Portuguesa, Literatura e Comunicação Profissional.

Os resultados obtidos com o questionário, enfatizaram a pertinência do componente curricular Língua Portuguesa, Literatura e Comunicação Profissional para a formação integral do aluno.

Se o domínio da linguagem verbal, "falar e escrever bem", como pontuado anteriormente, pode ser um mecanismo que reforça a autoconfiança dos alunos da modalidade EJA, é a própria linguagem verbal que insere o indivíduo no mundo, não só o do trabalho, uma vez que o capacita e permite que esse atue de forma mais consciente e transformadora.

Ressalta-se, ainda, a importância da modalidade EJA profissionalizante, mesmo sendo esse um terreno inconstante perante os registros legais e com tímidos dados de estudos, uma vez que o índice de abandono dos bancos escolares é considerável ou, ainda, considerando o elevado número de pessoas que não tiveram acesso à educação na idade considerada adequada. Essa é uma política pública que pode ser aprimorada, mas que deve ser mantida. 


\section{Referências}

BARATO, J. N. Fazer bem feito: valores em educação profissional e tecnológica. Brasília: UNESCO, 2015.

BRASIL. Ministério da Educação. Programa de Integração da Educação Profissional e Técnica de Nível Médio Integrada ao Ensino Médio da Modalidade de Educação de Jovens a Adultos - PROEJA. Documento Base, 2007. Disponível em http://portal.mec.gov.br/setec/arquivos/pdf2/proeja_medio.pdf. Acesso em: 11 nov. 2017.

CENTRO PAULA SOUZA. Mapeamento das Escolas Técnicas - Dados Gerais, Eixos Tecnológicos e Cursos Oferecidos. Mapeamento das Unidade do Centro Paula Souza 2016 $2^{\circ}$ semestre. São Paulo. Disponível em http://www.cpscetec.com.br/cpscetec/publicacoes/bdcetec/Unidades20162Semestre.pdf. Acesso em: 10 nov. 2018.

CITELLI, A. Comunicação e educação. A linguagem em movimento. 3.ed. São Paulo: Senac, 2004.

FIGARO, R. Relações de comunicação no mundo do trabalho. São Paulo: Annablume, 2008.

MANFREDI, S. M. Educação profissional no Brasil: atores e cenários ao longo da história. Jundiaí-SP: Paco, 2016.

MORAES, F. de; KÜELLER, J. A., Currículos integrados no ensino médio e na educação profissional: desafios, experiências e propostas. São Paulo: Senac, 2016.

MOURA, D. H.; HENRIQUE, A. L. S. PROEJA: entre desafios e possibilidades. HOLOS, ano 28, v. 2, 2012, p.114-129. Disponível em:

http://www2.ifrn.edu.br/ojs/index.php/HOLOS/article/view/914/536. Acesso em: 12 nov. 2017.

PETEROSSI, H. G.; MENINO, S. E. A formação do formador. São Paulo: Centro Paula Souza, 2017.

PONTUSCHKA, N. N. Concepções e práticas de ensino e aprendizagem na educação de jovens e adultos. In: MORAES, C. S. V. (Org.). Educação de Trabalhadores por Trabalhadores: educação de jovens adultos e formação profissional. São Paulo: Editora Sociologia e Política, 2013. p. 131-166

TARDIF, Maurice. Saberes Docentes e Formação Profissional. 17.ed. Petrópolis, RJ: Vozes, 2014.

ZABALA, A. A prática educativa: como ensinar. Porto Alegre: Artmed, 1998. 